\title{
LA POLÍTICA NASA Y EL CLIENTELISMO en el municipio de Páez, Cauca
}

\author{
LuCÍA EugEnia MenESES \\ Grupo de Estudios Sociales Comparativos (GESC)
}

UNIVERSIDAD DEL CAUCA

lucuweb@hotmail.com

\begin{abstract}
Resumen
A CONSTITUCIÓN POLÍTICA DE I99I HA REAFIRMADO EN LOS PAECES ALGUNAS FORMAS tradicionales de hacer política, pero produjo también cambios socioculturales en distintos ámbitos de la vida social. En el caso estudiado se resalta la manera como después de esta y a partir de las transferencias de recursos a los resguardos indígenas del municipio de Páez, empezaron a constituirse redes clientelistas que se fundamentaron en las posiciones de poder que empezaron a desempeñar algunos líderes en las organizaciones indígenas. Estas redes de clientela, sin embargo, no constituyen un sistema idéntico al que practican los partidos políticos tradicionales. En este caso se trata, quizá, de una variación o de un sistema particular que se compagina como una nueva forma del ejercicio de la política local. No obstante, el proyecto indígena Nasa subsiste todavía en la reivindicación de la identidad política étnica.

PALABRAS Clave: constitución política, clientelismo, elites, control social, instituciones, orden, política, desarrollo, departamento de Cauca (Colombia).
\end{abstract}

\section{Abstract}

THIS ARTICLE EXAMINES THE WAY OF DOING POLITICS IN THE INDIGENOUS MUNICIPALITY OF Paez since a new National Charter was formulated in I9gI. Although this National Constitution enhanced the indigenous law in Colombia, some political effects started to appear particularly from the transference of substantial funds for the indigenous territories. Here, I analyse the emergency of patron-client relations which turn up after the law imposed by the Constitution attempted to support Nasa communities in Paez municipality. Although there are similarities to the traditional patronclient relations developed by the so called traditional parties, liberales and conservadores, I believe there are differences which suggest to think in a different set of relations. However, the spirit of keeping a political identity still remains.

KEY wORDs: Political Constitution, clientelismo, elites, politics, social control, institutions, orden, development, Cauca (Colombia).

Revista Colombiana de Antropología

Volumen 38, enero-diciembre 2002, pp. I05-I30 


\section{INTRODUCCIÓN*}

A PARTICIPACIÓN DE LOS INDÍGENAS EN LA POLÍTICA NACIONAL SE HA incrementado sustancialmente en las últimas décadas, cons- tituyéndose en un asunto que ha despertado la atención de distintos estudiosos(as) de lo social (Laurent, I998; Jackson, I998). Los logros alcanzados por las luchas indígenas han estado apoyados, además, por el clima de reivindicaciones identitarias en los contextos regionales y, principalmente, por el ambiente legal y político que generó la constitución de I99r.

Cada vez son más las organizaciones y movimientos políticos indígenas en el país que a partir de la "instrumentalización de la identidad (diferencia)" buscan obtener el reconocimiento de derechos particulares y la defensa de intereses colectivos (Gros, I997: 2I), además de espacios políticos locales, regionales y nacionales. Sin embargo, el proceso de institucionalización de los movimientos sociales, así como su acceso a espacios de poder en los que ciertos líderes tienen la oportunidad de decidir y planear, intentando cambiar o, por lo menos, afectar las estructuras políticas y los órganos de poder de la sociedad dominante son recientes.

En el municipio de Páez -departamento de Cauca- existen instituciones como el cabildo, la Asociación de Cabildos y la alcaldía que potencialmente pueden controlar el comportamiento social estableciendo pautas que se canalizan en una dirección determinada. Según Berger y Luckmann (I998: 76), desde un punto de vista teórico estas pautas ayudarían a mantener espacios de poder. Pero, ies factible para los indígenas acceder realmente a espacios de poder que permitan afectar las estructuras políticas hasta ahora dominantes? O, por el contrario, ¿es posible pensar que en el esfuerzo por acceder a dichas estructuras terminen repitiendo las formas políticas

* Agradezco a los evaluadores sugeridos por la Revista Colombiana de Antropología, quienes con sus comentarios permitieron re-escribir y dar nueva forma al texto. También a las personas que narraron su historia de vida y a aquellos de una $u$ otra forma animaron la escritura de estas experiencias. Muchas ideas aquí expuestas fueron discutidas con otros colegas y amigos, aun cuando lo planteado no es su responsabilidad. dominantes? Estos interrogantes permiten sugerir que en el campo de lo político no hay nada cierto y estable, y que las condiciones y actores que determinan esos espacios son moldeables y cambiantes. Como lo señala Escobar (I999: 150), en lugar de medir el éxito de los movimientos es necesario indagar sobre la manera 


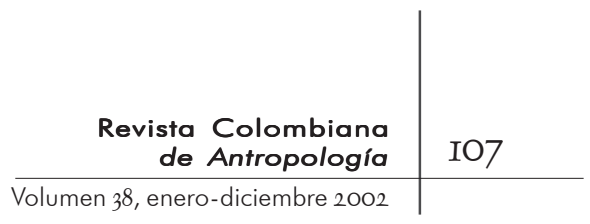

como sus discursos y prácticas transforman los discursos dominantes y las prácticas excluyentes.

Los análisis sobre política indígena son variados (véase la bibliografía) y comprenden diversas perspectivas y disciplinas -sociología, antropología, política-; sin embargo, muchos se quedan en análisis teóricos y son pocos los que describen y desarrollan las ideas de las maneras particulares de hacer política y su significado en el ámbito local. Este artículo se orienta en tal sentido, al presentar las diversas formas de hacer política que se generaron en el territorio administrativo Páez ${ }^{1}$ a raíz de la institucionalización del movimiento político Nasa y del acceso al poder por parte de sus líderes, resaltando los cambios y las persistencias sociales en la manera de hacer política, de acuerdo con el contexto social y cultural ${ }^{2}$. En el caso analizado se resalta cómo después de expedida la constitución política de I99I y, específicamente, a partir de las transferencias de recursos del estado central a los resguardos indígenas del municipio de Páez, comenzaron a constituirse redes clientelistas, basadas en las posiciones de poder que empezaron a desempeñar algunos líderes en las organizaciones indígenas. Estas redes de clientela, sin embargo, no constituyen un sistema idéntico al de los partidos políticos tradicionales; se trata, quizá, de una variación o de un sistema particular que se compagina como una nueva forma del ejercicio de la política local. No obstante, el proyecto indígena Nasa persiste en reivindicar la identidad política étnica.

El artículo está dividido en otras seis secciones. En la primera se presenta, a manera de introducción, el contexto social en que se enmarca el grupo indígena nasa del municipio de Páez y se describen las formas de hacer política antes de I99I. En la segunda se analiza la participación de los nasa en la política y la institucionalización de su movimiento. En la tercera se trata lo relacionado con la constitución de I99I y sus implicaciones y efectos políticos para la comunidad en general; luego se abordan al etnicidad, el clientelismo, el conflicto generacional y las elites como un reflejo de la forma de hacer política en el municipio. A continuación se describen las formas políticas de planeación

I. Se llamará Páez al espacio político y administrativo reconocido institucionalmente. Cuando me refiera a la población indígena la llamaré nasa, y a la población negra o campesina por su referente, según sea el caso.

2. En este trabajo no se tienen en cuenta otras organizaciones presentes en la zona, como los grupos protestantes -Testigos de Jehová, Pentecostales, Alianza Cristiana-y la iglesia católica. Estas constituyen un aspecto interesante para investigaciones futuras, pues si bien mantienen un orden ético y moral también se fundan en redes de clientelas y sistemas de relaciones sociales. 
realizadas en los resguardos y el municipio, en relación con los planes de desarrollo. Y, por último, se presentan algunas conclusiones y comentarios en cuanto a la importancia de esta situación para investigaciones antropológicas futuras.

\section{LOS NASA, SU ESCENARIO Y CONTROL SOCIAL}

OS NASA OCUPAN LA MARGEN ORIENTAL DE LA CORDILLERA CENTRAL COlombiana, en el nororiente del departamento de Cauca. Organizados en resguardos ${ }^{3}$ presididos por cabildos ${ }^{4}$, actualmente se encuentran dispersos en los municipios de Inzá y Páez ${ }^{5}$, formando

3. La información se recogió durante los ocho talleres que se efectuaron para elaborar el plan de desarrollo 200I-2003 del municipio de Páez, que duraron entre dos y tres días en ocho zonas, así: zona oriente: corregimiento de Río Chiquito; zona sur: corregimiento de Itaibe; zona sur-alta: resguardos de Cuetando, Ricaurte y Togoima; zona urbana: cabecera municipal de Belalcázar; zona centro: resguardos de Avirama y comunidades negras; zona occidente: resguardos de Mosoco y San José; zona alta: resguardos de Vitoncó, Chinas, Lame y Suin; zona alta-baja: resguardos de Tóez, Wila y Tálaga. Aunque algunas consideraciones pueden ser compartidas, la mayoría de las notas se recogieron en el resguardo de Tálaga, debido a la mayor permanencia allí.

4. El cabildo indígena es la forma de organización social y política, de origen colonial, y está presidido por un gobernador. El médico tradicional, que en muchos casos es pasivo y cuya labor es poco visible, precede al gobernador como autoridad; la labor del gobernador, por el contrario, es activa y está en relación con la comunidad y con el mundo exterior. En la comunidad y fuera de ella se reconoce la labor que realiza el sabio o médico tradicional en la curación de enfermedades, la solución de problemas comunitarios, además de su papel de consejero y ejemplo de vida (véanse Portela, I988, 1995; Quintero, 1994).

5. Sin embargo, hay registro de paeces en los departamentos de Huila, Caquetá, Putumayo y Valle del Cauca. La literatura sobre esos asentamientos es poca. Según referencias personales, han sido formados por desplazados de la violencia de los años I950 y, recientemente, por familias desplazadas por la tragedia del río Páez, que no se acogieron a los planes y programas de los reasentamientos. la zona llamada Tierradentro. Las leyes que controlan la vida social y política interna están dadas por el cabildo de cada resguardo, y buscan, como en toda sociedad, conservar el orden. Muchas de las que rigen los cabildos indígenas son los principios culturales de Juan Tama, figura mito en la tradición nasa; algunos de estos se ponen en práctica hoy, preservando su tradición. En este caso, la política se fundamenta y legitima en lo sagrado, lo que determina las acciones políticas, los valores éticos y morales y las representaciones ideológicas y religiosas (Ravis Giordani, I975, citado por Jimeno, I988: 265).

En los resguardos del municipio de Páez los conflictos internos se resuelven en asambleas comunitarias, siguiendo el siguiente proceso: el cabildo, mediante los comisarios de cada vereda, cita a la comuni- 


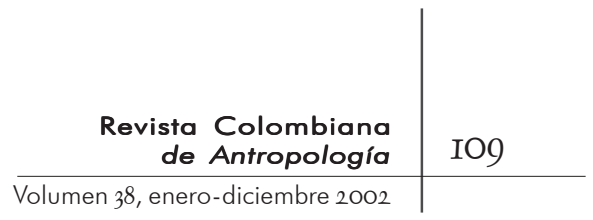

dad a una fecha y hora determinada, anunciando el objetivo de la reunión; en la asamblea se anuncian de nuevo los motivos, nombrando las faltas de la persona acusada; en ese momento los acusadores pueden repetir la acusación; sin embargo, la comunidad es la que, acogiéndose a las normas, establece las correcciones a las faltas más comunes, que en caso de hurto, por ejemplo, puede ser la devolución de lo robado.

El proceso normativo seguido en la solución de conflictos ${ }^{6}$ sigue el orden siguiente: llamado de atención verbal o, en algunos casos, escrito; encierro en el calabozo ${ }^{7}$; castigo en el cepo -incluye fuete $-^{8}$; trabajo comunitario, primero en el resguardo y luego en todos los resguardos del municipio; y, finalmente, el destierro del resguardo. Las acciones descritas ratifican lo mencionado por Santana: "El cabildo juega el rol de guardián de cierta disciplina social y de normas éticas y de responsabilidades que son la base de la cohesión social del grupo comunitario" (I995: II8-II)).

6. Este proceso varía de acuerdo con las comunidades, pero se mantienen el cepo,

En términos teóricos, la autoridad, un concepto que alude al poder, se define como: "La capacidad para influenciar el comportamiento de otro y/o (sic) lograr influencia sobre el control de las acciones valoradas"; en este caso, el superior "tiene un derecho reconocido" (Smith, 1979: 33-34). Entre los nasa este sentido de autoridad para convocar a la comunidad lo tiene el cabildo, encabezado por el gobernador, elegido por aquella.

Una forma de control social que genera conflicto interno, del que muy pocas personas hablan pero que es común, es la brujería, en la que según Henman (I98I: 9I) el maleficio es causado por envidia, celos o codicia, generadas por las tensiones de vivir en una sociedad pequeña e igualitaria, y cuyo desenlace es, primero, las enfermedades y las desgracias y, finalmente, la muerte.

La acción de los brujos ${ }^{9}$ en contra

(Gómez, I989: 342).

7. En algunas casas de cabildo se han construido pequeñas celdas en las que se encierran personas que han sido vistas y se alcanzan a detener cometiendo el delito y cuya sanción se aplaza, o personas en estado de embriaguez.

8. El látigo es la representación del rayo o el trueno, lo mismo que la vara de chonta. Estas últimas son de uso exclusivo de las autoridades del resguardo. El rayo y el trueno "habita en las alturas y tiene la capacidad de castigar y matar" (Gómez y Ruiz, I997: 5I).

9. El brujo sabe de plantas y siente la seña como un médico tradicional bueno; algunos indígenas aseguran, incluso, que ha avanzado más en sus poderes porque domina completamente las propiedades de las plantas bravas o peligrosas. Trata el mal con las "señales del diablo y todos los secretos de la hechicería". En el tratamiento del mal puesto por los brujos los sabios o médicos tradicionales ponen sus conocimientos a prueba, "pero a pesar de que los indígenas acuden donde los brujos para hacer maldades estos no son respetados por la 


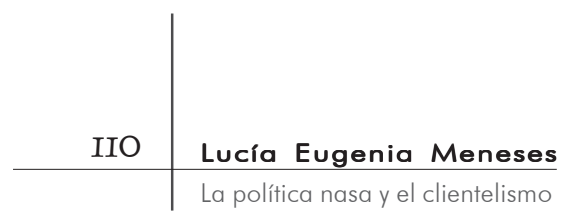

comunidad, ni se les tiene en cuenta en la toma de decisiones, ni en las actividades socioculturales" (Henman, I98I: 9I-92). Otra diferencia entre el brujo y el médico tradicional está en lo económico: el primero "necesariamente trabaja a cambio de dinero, no hace favores gratuitos a ninguna persona, siempre espera recompensa a cambio de sus servicios" (44).

IO. En este ejemplo la referencia es para el resguardo de Tálaga en el que, según la familia afectada, la acción de un brujo mató a tres personas de la misma y dejó loca a una niña.

II. La guardia cívica está compuesta por los mismos indígenas, armados con palos, y controla el orden en la comunidad durante las fiestas y las reuniones o en situaciones en las que hay indicios de inseguridad o de amenazas colectivas.

toridades indígenas. No obstante, en 2000, después de concertar, esos grupos reconocieron la autoridad y autonomía de las autoridades nasa en la solución de los conflictos internos. Así, por ejemplo, en las fiestas de san Juan realizadas en el resguardo de Tálaga en 2002, un integrante de un grupo armado, en estado de embriaguez, hizo tiros al aire; la guardia cívica ${ }^{11}$ lo encerró en el calabozo con la venia de su comandante, presente en la fiesta.

En otras oportunidades, la presencia de esos grupos armados en situaciones de conflicto y desorden comunitarios está antes que las decisiones del cabildo; en estas condiciones su acción se limita a mantener el orden, a detener a los implicados, incluso hasta llevarlos a la presencia del cabildo. Así, aun cuando esa autoridad no se reconoce como legítima, en la práctica la presencia de esos grupos ayuda a mantener el orden en determinadas condiciones.

Según la ley 246 de coordinación, la justicia propia y la occidental intentan colaborar, en teoría, en la solución de problemas en las comunidades indígenas. En Tierradentro las actividades de coordinación consisten en que cada resguardo acuerda con la fiscalía del municipio los casos en los que actuará cada una; en el municipio de Páez aún no se trabaja en conjunto. 


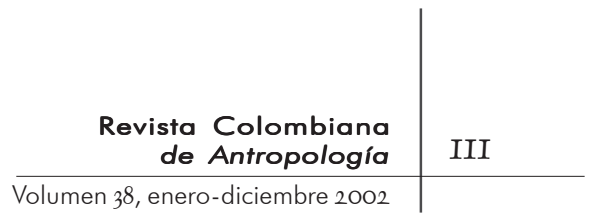

En las relaciones externas los nasa actúan colectivamente al ser representados por las asociaciones de cabildos y por los gobernadores, de acuerdo con los valores políticos del grupo. Las acciones políticas externas se sustentan en el símbolo de poder político, que es la vara de chonta o vara de mando; la presencia de un indígena con una vara implica respeto y autoridad en cualquier sitio (para una mejor descripción de la vara de chonta, véase Bedoya, I990).

Estas formas de control social entre los paeces contrastan con los diferentes modos de interacción con otros grupos sociales con los cuales se han relacionado históricamente y con los que definen políticamente sus formas de gobierno y control social; aspectos que aun siendo fundamentales para su vida social no están exentos de influencias y transformaciones.

\section{El movimientio pOLÍtico indígenA NASA, LOS PARTIDOS POLÍTICOS \\ Y SU INSTRUMENTALIZACIÓN}

A PARTICIPACIÓN DE LOS INDÍGENAS EN LA POLÍTICA NACIONAL NO HA estado al margen del sistema político y de las redes de cliente- la de los partidos tradicionales -liberal y conservador-, que se han repartido y utilizado los votos de aquellos para ganar diversos comicios electorales. Los mayores ${ }^{12}$ recuerdan la guerra entre liberales y conservadores en los años I950, en la que muchos debieron vivir fuera de sus ranchos -dejando la familia y las tierras para salvar sus vidas-, otros permanecieron como presos políticos en las cárceles de Silvia y Popayán, y unos más fueron muertos en el peñón de Tálaga, sitio estratégico situado en la entrada del cañón alto del río Páez y que durante la conquista fue un lugar de lucha de los nasa, que ocupaban este territorio, en contra de los españoles.

I2. Entrevistas a Eufemia Perdomo (85 años, indígena Páez, que en la actualidad resi-

Los políticos tradicionales codiciaron los de en Popayán) y a Francisca votos de los indígenas desde IOI2, "cuando Lucumí (70 años, de ascendenla ley colombiana autorizó el voto a quienes cia negra, residente en el deparsupieran leer y escribir y tuvieran propiedad raíz" (Bonilla, I977: 35-36); al respecto sería interesante analizar en los archivos la cantidad de indígenas considerados letrados en 
Colombia y el número de votantes durante esos años. De otro lado, hasta la promulgación de la constitución política de I99I, y de acuerdo con la ley 89 de I89o, los indígenas eran considerados menores de edad, por lo cual no podían ejercer su derecho al voto. Sin embargo, en el resguardo de Tálaga se recuerda todavía cómo, durante las elecciones, el dedo índice se untaba de tinta roja o azul. Algunas personas se apostaban a la entrada de los pueblos con remesa o con dinero y pagaban el voto, y a la salida los votantes debían mostrar el dedo, según el color del partido por el que habían sufragado; en ese entonces, los colores podían ocasionar conflictos familiares y comunitarios.

En una familia extensa de filiación liberal, por ejemplo, el abuelo salía a votar con los hijos, las nueras y los nietos. "Se lucía el dedo índice con orgullo; si su candidato era el ganador se realizaban fiestas y había riñas y peleas" (Eufemia Perdomo, ama de casa, 85 años, 200I). Otra forma de conseguir los votos de los indígenas, antes y en menor medida ahora, es la compra de los líderes, quienes deben convencer a los demás para que voten por un candidato a cambio de recibir obras para la comunidad. Esta modalidad se lleva a cabo desde inicios del siglo veinte, cuando se "consolidaron los partidos tradicionales", especialmente el liberal (Bonilla, 1977), y sirve para ilustrar cómo la política tradicional ha estado cercana a la política nasa, sobre todo en Tálaga y en los resguardos de la zona norte del municipio.

A pesar de que en el departamento de Cauca los movimientos indígenas se hacían sentir desde décadas anteriores, el movimiento político indígena en Páez es relativamente reciente, pues sólo a partir de I993 se organizaron para elegir sus candidatos a la administración del municipio de Páez, y entre 1992 y I993 empezó el trabajo que llevó a la alcaldía a un indígena. Lo anterior muestra que, como resultado de dos hechos, los cambios no se hicieron esperar y se acentuaron: la expedición de la carta política de I99I y la tragedia del río Páez ${ }^{13}$, eventos que afirmaron y transformaron el modo de entender la política en la región.

Ahora bien, a pesar de que en el Cau-

I3. El análisis de las consecuencias políticas del proceso de reubicación, pero sobre todo de la concepción de la tragedia del río Páez y del desastre como oportunidad política, de modernización y desarrollo, constituye materia para otro artículo. ca el movimiento político tenía una trayectoria larga por el trabajo que había efectuado el Consejo Regional Indígena del Cauca (Cric), en Páez el movimiento indígena no se consideraba parte de esa organización, por la poca aceptación que 


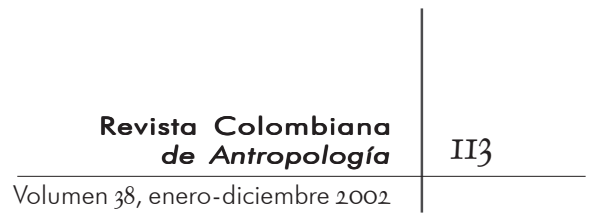

tenía en el municipio. La creencia de que los miembros del Cric eran guerrilleros -comúnmente chusma-, distanciaba la actividad política en varios resguardos de Tierradentro, situación que se vio favorecida, en la mayoría de los casos, por el mal ambiente hecho por los padres católicos, quienes en su misión por los caminos de la zona se encargaban de satanizar a los pocos líderes que se atrevían a iniciar algún trabajo organizativo ${ }^{14}$.

Los indígenas dicen que "por la falta de experiencia se cometieron muchos errores que aún no se terminan de pagar"; sin embargo, ese fue su primer intento de administrar el territorio indígena desde la alcaldía, administrada hasta entonces por las diversas corrientes del Partido Liberal. En este sentido, el senador Jesús Enrique Piñacué, de la comunidad Páez, señala que:

La participación política de los indígenas ha estado en el limbo en la nueva construcción de la política; se inicia sin experiencia pero con las ganas de comenzar un nuevo proceso. Los sinsabores de los triunfos políticos aun se observan en las clases que participan del gobierno (Talleres Plan de Desarrollo, febrero, 200I).

En 1995 el Partido Liberal retomó el poder de la administración del territorio municipal de Páez. Los indígenas mismos hicieron prácticas de corrupción administrativa comunes en años anteriores, mediante el pago de votos y silencio con bultos de cemento, remesas o unos metros de manguera. Uno de los casos mencionados tuvo que ver con un alcalde, investigado luego por falsedad de documento y otros cargos.

Sahlins (1963) ha señalado que tal sentido de reciprocidad en la política se presenta también en otras sociedades y culturas, como las del Pacífico. Siguiendo su interpretación, la práctica conocida como politiquería, una característica de las relaciones patrón-cliente, estaría siendo articulada con el sentido de reciprocidad en el contexto local (véase también Schmidt, I974; 1977).

A pesar de las dificultades, el movimiento indígena en Páez adquirió nuevos ímpetus, por lo que entre 1995 y 1996 se reunieron algunos líderes que habían observado y vivido procesos en otros sitios,

I4. En la actualidad, el Cric dirige la Asociación Indígena del Cauca (AIC), administradora del régimen subsidiado en salud (ARS). La AIC ha sido un medio para divulgar un discurso político de reconocimiento de los derechos en zonas y comunidades de Tierradentro y otros grupos indígenas, como los de la costa pacífica caucana, en los que la actividad del Cric se conocía pero no se seguía. En consecuencia, en un comienzo la AIC fue un medio para conseguir un fin político. 
e iniciaron el proceso de organización de los resguardos en la Asociación de Cabildos del Municipio de Páez-Nasa Cha-Cha-, gestora del movimiento y aliada de la Alianza Social Indígena. En I996 se conformó la Asociación, que reúne los catorce cabildos del municipio y cumple con los trabajos de administración de los resguardos.

Su actividad electoral sólo se inició en 2000, cuando se nombró un candidato del movimiento a la alcaldía municipal para el periodo 200I-2003, proceso que culminó en octubre de ese año con la elección del mismo, así como de una mayoría indígena al consejo -incluido el presidente-. Según los indígenas, la oportunidad de conseguir ese espacio era única en el municipio, pues las experiencias políticas no le daban credibilidad a los partidos tradicionales; a pesar de esto, la diferencia entre el elegido y el segundo -candidato de esos partidos-, fue de 200 votos, lo cual indica que si los otros candidatos hubieran hecho una coalición los indígenas no habrían podido elegir su alcalde. Esta es una oportunidad para que los Nasa del municipio hagan conocer su movimiento y puedan mantenerse en el mismo, lo que podrá evaluarse al finalizar el mandato del alcalde.

En teoría, el movimiento, evalúa el trabajo y la gestión del mandatario local y de los funcionarios municipales. Para los indígenas, "esta nueva oportunidad en el poder será diferente", debido a las evaluaciones mencionadas. Un líder señala que la vez anterior "se dejó solo al alcalde y por eso se cometieron tantos errores".

El programa de gobierno se denomina "En minga por el futuro de Páez", y tiene tres ejes fundamentales: salud, saneamiento básico y educación. El alcalde, formado como médico con dinero de los cabildos indígenas, tiene la responsabilidad, acompañado por el movimiento, de mantener el interés por el movimiento político en el municipio. Si bien este es reciente, los resultados electorales de 2000 lo convirtieron en nuevo actor político que puede marcar el quehacer político allí. En este caso, la disyuntiva es "isi ese nuevo actor se va a constituir alrededor de la pura defensa de los intereses étnicos y comunitarios o si va a intervenir en el debate político en nombre de los intereses de todos id est de la nación?” (Gross, 1997: 3I).

A pesar de estar habitado sobre todo por nasas, en Páez existen grupos negros y campesinos, que apenas empiezan a movilizarse políticamente por la reivindicación de derechos étnicos. 


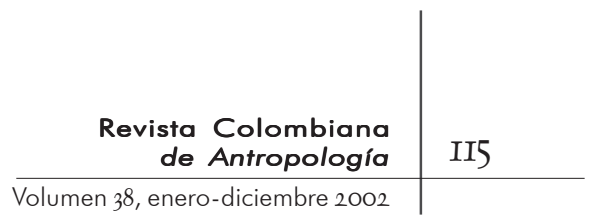

En los comicios electorales su unión su unión junto con los indígenas es visible, aun cuando cada grupo contaba con sus candidatos propios. Sin embargo, en los discursos de reivindicación y en la lucha por los derechos de los indígenas se los excluye ${ }^{15}$.

Según la opinión de algunos, el movimiento indígena -institucionalizado en la Asociación de Cabildos- debería dedicarse, antes que a conseguir votos, a reflexionar sobre las prácticas y los discursos político-identitarios, de desarrollo y modernización, además de filtrar las actividades institucionales que pasan a los resguardos, y a controlar y a ejercer la veeduría a los planes y programas de las instituciones estatales. Aun cuando no tiene el reconocimiento como partido político que exige la constitución sí tiene control social y político sobre el resto de la población del municipio; así mismo, adelanta una serie de programas de acción en los resguardos del municipio, que espera desarrollar articulado al programa de desarrollo rural de Tierradentro ${ }^{16}$ (DRT), financiado por la Unión Europea durante cinco años (2000-2005), el cual actuará en tres frentes: infraestructura social, producción y medio ambiente, educación y capacitación comunitaria.

Es decir, el movimiento se ha institucionalizado, confirmando la tesis de Gross, quien señala que "algunos funcionan como Ong's (sic) con vocación de etnodesarrollo, con quien el Estado (sic) debe contar y trabajar" (I997: 46). Este es uno de los retos que debe enfrentar el movimientos indígena en relación con el contexto político que se les presenta en la actualidad.

En este sentido, el movimiento indígena, los cabildos y la asociación de cabildos en conjunto con la alcaldía indígena han establecido estrategias para mantener el orden social y político, diferentes a las utilizadas hasta entonces, basadas en la manera de hacer política de los partidos tradicionales. De otro lado, y tal como ocurre en otras regiones del país, los gobernadores que conforman la asociación de cabildos se han reunido para apoyar su alcalde, lo cual puede interpretarse como una consecuencia del nuevo marco legal de respeto por las autoridades indígenas y la cultura local propiciado por la constitución política, que ha servido también para fortalecer el orden interno en la sociedad Páez.

I5. Así lo hacía sentir un estudiante de la Normal de Belalcázar al mencionar el escaso apoyo que recibían los no indígenas -negros y campesinos- para acceder a la educación superior.

I6. Dicho programa ha sido gestionado por los indígenas, ayudados más por particulares que por fundaciones. Las actividades deben realizarse en los municipios de Inzá y Páez. El manejo de esos recursos constituye un reto para los indígenas. 
En efecto, los líderes indígenas se muestran muy preocupados por la organización administrativa y territorial, pues está por verse si el estado central considera al municipio viable financieramente. El problema es que allí, como en muchos otros municipios del país, la alcaldía se ha convertido en una bolsa de empleo, para maestros especialmente, y de cargos con los que suelen pagarse los favores políticos de la clase dirigente, situación que sumada al endeudamiento con el estado central tiene el municipio al borde de la quiebra. En caso de que el municipio como entidad administradora del territorio deje de operar, los líderes han considerado la posiblidad de crear una entidad territorial indígena (ETI), aun cuando estas unidades, creadas por la constitución, no han sido reglamentadas. Se necesitaría, entonces, el saneamiento de los predios no titulados como resguardos dentro del municipio ${ }^{17}$, y el pago de impuestos por parte de los indígenas, lo que permitiría mantener un consejo o entidad administradora, como la Asociación de Cabildos, la cual cumpliría con las funciones ${ }^{18}$ estipuladas por la ley orgánica de ordenamiento territorial. Es decir que algunos consideran que la preocupación por la viabilidad del municipio se resolvería con la adopción de la ley sobre ETI, que permitiría a la Asociación de Cabildos tener más poder en la administración del territorio indígena así como del mestizo y el negro.

Aun cuando la mayoría del territorio está reglamentada por títulos de resguardo y administrada por los cabildos indígenas, la administración de la municipalidad es cada vez más difícil por la falta de recursos que permitan satisfacer las necesidades

I7. Existen dos corregimientos con población negra, ltaibe (al sur) y Río Chiquito-al oriente-, zonas que no pagan impuestos pero que tampoco están tituladas como propiedades colectivas o privadas. De acuerdo con conversaciones sostenidas con algunos moradores del lugar, la mayor parte de los predios de ltaibe pertenece legalmente a la iglesia católica, uno de los mayores deudores de impuestos del municipio.

I8. Para una descripción mejor de las funciones de los llamados consejos territoriales de las ETI, véase Jackson (I998: 287-3I4.). básicas de la población, lo cual no parece tener solución a corto y mediano plazo debido a la crisis cada vez mayor por la que atraviesan las unidades administrativas locales.

Considero que la creación de una ETI tampoco permitirá superar la crisis, pues podrían acentuarse ciertas diferencias políticas por la administración del territorio entre la Asociación de Cabildos, algunas asociaciones apenas nacientes como la Asociación de Morenos, Mestizos y Campesinos de Páez (Acomomecap) y personas críticas con cierto poder. 


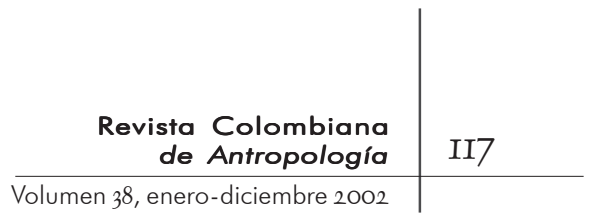

Además, existen territorios que aun cuando pertenecen a la municipalidad, en la práctica, establecen relaciones culturales, económicas, políticas y sociales con el departamento de Huila -corregimientos de Río Chiquito e Itaibe-, por lo cual no podrían formar parte de la ETI. En consecuencia, y para buscar soluciones a la crisis del municipio, los líderes de Paéz deberían establecer relaciones con municipios vecinos como Inzá, Silvia y Totoró, que están más cerca y con los que existen más relaciones sociales y económicas.

\section{LA CONSTITUCIÓN DE I99I, EL CLIENTELISMO Y LA POLÍTICA NASA}

AS FORMAS EN QUE LOS GRUPOS HUMANOS SE RELACIONAN ENTRE SÍ Y con los demás están mediadas por unas leyes de origen que, teóricamente, se convierten en derechos propios, los cuales según el artículo 246 de la constitución política de Colombia deben ser respetados y acatados en el territorio, siempre y cuando no vayan en contra de la constitución y las leyes.

Aunque la constitución de I886 y las reformas constitucionales posteriores no defendían la diversidad étnica y cultural en Colombia, la situación de los indígenas había empezado a cambiar desde los años I960 (Correa, I992: 7I-IOI), tal como lo demuestran el reconocimiento hecho por el Ministerio de Salud a los conocimientos médicos tradicionales, la exoneración del servicio militar para los indígenas y los derechos otorgados por el código minero con respecto a los recursos del subsuelo (Jackson, I998: 290-29I). Sin embargo, aun cuando la ley garantizaba estos derechos en la práctica nunca existieron.

Ahora bien, la carta de I99 - un proyecto político nacional en el que los nasa participaron y por medio de la cual muchos líderes accedieron a instancias estatales- reconoció derechos especiales a los grupos indígenas, lo cual produjo una situación de cambios políticos (para una mayor descripción sobre la constitución política de Colombia y los grupos étnicos, véanse Triana, I992: IO3-II3; Valencia y Poveda, I992: II5-I22). Uno de los principales cambios establecidos por la constitución fue la transferencia anual de dineros de la nación a los cabildos indígenas, que los han convertido en administradores de los recursos y a 
su gobernador en el representante legal de la comunidad con respecto a los mismos. Si bien dichos recursos han permitido satisfacer algunas necesidades básicas de las comunidades, entre los indígenas -y especialmente entre los líderes- han despertado el afán por administrarlos. Ello se refleja en las campañas para elegir los gobernadores de los cabildos, que actualmente no se diferencian mucho de las realizadas por los políticos de los partidos tradicionales para la elección de alcaldes.

Los líderes hacen promesas, que la mayoría de las ocasiones no corresponden a las expectativas de las comunidades: puentes donde no hay río o, si es necesario, pavimentar el río. Es decir que los paeces están haciendo política de forma similar a la de la politiquería tradicional y sus redes clientelistas, que rechazaban antes $^{19}$. Así, los espacios de poder ganados por los indígenas son producto, algunas veces, de acciones politiqueras y clientelistas aprendidas en su interacción con los políticos tradicionales.

Pero en el caso de los nasa, al menos, es claro cómo las redes clientelistas emergieron después de I99I, con el acceso de los indígenas al manejo de sus propios recursos, pues desde antes algunos líderes hacían parte de las redes de los políticos tradicionales.

\section{ETNICIDAD, CLIENTELISMO \\ Y CONFLICTO GENERACIONAL}

L CliEnTElismo EN COlOMBIA HA SIDO ESTUdiado, SOBRE TODO, DES-

- de una perspectiva que se centra en la acción de los partidos L tradicionales en comunidades rurales campesinas. Para el caso de comunidades indígenas la bibliografía es poca, por lo cual el concepto se tratará con ciertas precauciones.

El clientelismo está presente en las relaciones sociales de cualquier naturaleza y no sólo en las de tipo político, y se asocia con el autoritarismo y el paternalismo. Es una relación asimétrica que se apoya en la diferencia de poder entre

I9. Tocancipá (2000: 54), presenta un planteamiento similar: "A pesar de haberse introducido en Colombia nuevos movimientos políticos con grupos de población joven, lo que se encuentra es una renovación del sistema político tradicional". las partes, y es una constante en la política en Colombia que se configura en las regiones. A pesar de lo anterior, no existe un sistema único de clientelas, sino variaciones locales que pueden ser remanentes o parte de redes más grandes. 


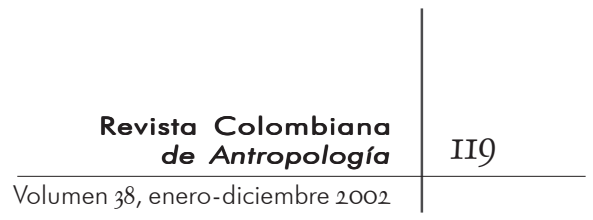

Scott, citado por Leal y Dávila (I994: 39) lo define como "una forma de intercambio interpersonal '(...) que implica una larga amistad instrumental en la cual un individuo de más status socioeconómico (patrón) usa su propia influencia y recursos para proporcionar protección y/o (sic) beneficios a una persona de menos status (cliente); a su vez, este corresponde al patrón al ofrecerle apoyo y asistencia general, incluidos sus servicios personales”".

En el municipio de Páez las redes clientelistas no se tejen sólo con los políticos tradicionales, sino que se han formado también alrededor de los indígenas que tienen un papel determinado en la Asociación de Cabildos o puestos burocráticos en la alcaldía, el hospital y en el Programa Tierradentro de la Unión Europea. Estas redes enlazan relaciones de poder y decisión que determinan luego un conjunto de nuevas relaciones de dependencia alrededor de grupos de personas que ocupan esas posiciones privilegiadas. Es posible que estas redes de clientela locales se formen sobre estructuras regionales o nacionales, y aunque no se relacionen directamente con los políticos tradicionales, es posible inferir que haya un efecto de mimesis por parte de ciertos líderes que han participado antes en la manera de hacer política de aquellos.

Así, por ejemplo, una persona A -patrón- con un puesto de cierto rango -presidente, vicepresidente de asociación, funcionario de la alcaldía, el hospital o, incluso, gobernador de cabildo- otorga puestos a B, C y D-clientes-. El puesto de B, C y D se concede en la institución en la que A detenta poder o en otras, de acuerdo con su capacidad de gestión. Los cargos pueden ser similares o más bajos según la posición que ocupe A en la estructura social y política de la institución. En la mayoría de los casos, B, C y D son parientes consanguíneos -hermanos-, o afines -cuñados- de A, o hijos de líderes de los resguardos que votaron o le ayudaron a conseguir votos. Se sabe de un caso en el que el cliente B no tenía la capacitación ni las aptitudes necesarias para desarrollar la labor asignada. A pesar de esta limitación, el patrón insistió en la permanencia de B en su trabajo, resaltando su autoridad y poder de decisión.

Junto con las relaciones clientelistas se encuentran las de compadrazgo, pues los patrones o líderes con más alto estatus son las personas ideales para ser padrinos en los diversos ritos católicos -bautismo, confirmación y matrimonios-. Según González (I994: 268), estas relaciones pueden extenderse por generaciones, pues 
el clientelismo, como un sistema diádico de prestaciones y contraprestaciones no formalizado jurídicamente, tiene la fuerza de su cumplimiento en el código de honor de patrones y clientes. En el municipio de Páez aún no se conocen casos de relaciones clientelistas en que Nasas paguen sus favores políticos con dinero contante y sonante; sin embargo, esto no los hace invulnerables al clientelismo ni los exime de verse comprometidos en este tipo de sistemas en un futuro ${ }^{20}$.

Allí, la apropiación de los recursos públicos y comunitarios no se sanciona y constituye una práctica que se generaliza ${ }^{21}$. Laurent señala que las transferencias "no han preservado a las comunidades de prácticas clientelistas y de robos" (I998: 95; véase también Zambrano, I997: 4-5). La pugna por conseguir cargos en el cabildo es frecuente a final del año, cuando este se elige. Los jóvenes bachilleres o con algún otro tipo de estudio, y que se llaman estudiados, creen tener mayor capacidad para administrar los recursos y, por ende, para acceder a los cargos, enfrentándose muchas veces con los mayores, para quienes es más importante conservar la tradición y la

20. Es de anotar que cada red de clientela implica un problema de escala. Es decir, que su cobertura puede variar, partiendo desde la estructura familiar y expandirse en el sistema de las relaciones sociales que la contiene.

2I. Es común el comentario de que al terminar su mandato un gobernador mejore su casa y tenga moto o carro.

22. Uno de los requisitos para recibir las ayudas para estudio es que después de terminar debe trabajarse en la comunidad para devolver los dineros invertidos.

23. El Seminario Indígena Páez (SIP) está ubicado en el resguardo de Tálaga, en la zona norte-baja del municipio, y anualmente recibe cerca de cien alumnos indígenas de Tierradentro, que desean realizar la básica secundaria o formarse como sacerdotes. Fue creado en 1985 y es una institución del vicariato de Tierradentro, que reproduce algunas formas culturales tradicionales como la agricultura, la música, las artesanías, y el cabildo, conformado por ocho jóvenes entre 12 y 25 años. autoridad.

Otra fuente de conflicto la constituyen los jóvenes que salen a realizar estudios superiores -universitarios o cursos especializados- con dineros de las transferencias, y que al finalizarlos no quieren regresar a la comunidad ${ }^{22}$, o que adquieren conocimientos que se enfrentan con las tradiciones comunitarias. Las profesiones con más demanda son la medicina o el derecho, y como los puntajes obtenidos no alcanzan para aspirar a dichas carreras en universidades públicas deben estudiar en instituciones privadas, más caras. En ese caso, la asamblea prefiere utilizar los recursos en obras comunitarias que solucionen problemas básicos y no para fines individuales.

Para algunos jóvenes como los formados en el Seminario Indígena Páez $(\mathrm{SIP})^{23}$ estudiar allí es "formarse como 


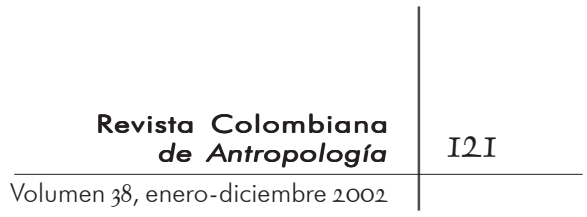

líderes cristianos que pueden desempeñar cargos diversos en el cabildo de sus comunidades de origen, o líderes de grupos organizados"; sin embargo, no desean ser gobernadores de sus resguardos, pues temen contar con poca experiencia para desempeñar el principal cargo en la comunidad.

Pero si bien los jóvenes se están formando para responder a los nuevos requerimientos sociales y políticos, las comunidades se quejan de su poca participación en la vida comunitaria, y ellos aducen las pocas oportunidades que se les brindan y la falta de asignación de responsabilidades en el cabildo (Talleres plan de desarrollo, 200I-2003, municipio de Páez).

Muchos esperan que el cabildo, ahora que tiene dineros de las transferencias, los envíe a estudiar a las capitales; sin embargo, y como se dijo, la mayoría no regresa y quienes vuelven tienen enfrentamientos o pasan a ocupar puestos en la administración municipal o en la asociación de cabildos. En este caso, el trabajo de liderazgo político y social es casi nulo, aun cuando han sido formados en la escuela y el colegio en el orden social indígena. Estos jóvenes pasan a formar parte de las elites indígenas, muchas de ellas dependientes de las redes clientelistas provenientes de la Asociación de Cabildos o la administración municipal.

Las ciencias sociales han estudiado las elites en las sociedades modernas -llamadas castas en el caso de los grupos tribales-; no existe una que abarque todos los campos sino un sistema complejo de minorías especializadas vinculadas entre sí e incorporadas al orden social de distintas maneras. En esas sociedades las elites se definen como las minorías que se mantienen aparte del resto de la sociedad por su preeminencia en uno o más de los siguientes factores: autoridad, mérito o recompensa. Algunas tienen más peso social porque su actividad tiene mayor importancia en la sociedad, y sus miembros se reclutan de distintas formas, dependiendo de su función.

Según Keller (I979: I8I), las elites pueden ser estratégicas, pues reclaman o tienen asignadas funciones e influencia sobre el conjunto de la sociedad; o fragmentarias, que tiene función en subsectores de esta. En algunas sociedades la dirección está a cargo de elites estratégicas, pues ningún estrato social desempeña solo las funciones sociales clave; en su lugar, tales funciones y las minorías que las cumplen son distintas y especializadas. Su justificación está en el mérito y en las cualidades particulares. 


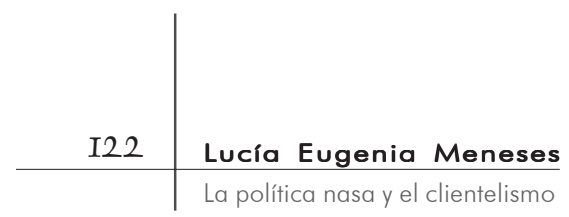

Cuando la sociedad es poco diferenciada las elites son pocas y su poder abarca todos los aspectos de la vida; y cuando la diferencia social es grande son muchas y especializadas En el caso del municipio de Páez, una sociedad muy poco diferenciada, las elites son reducidas y tienen mayor poder de decisión. La formada por los líderes de la asociación de cabildos, la alcaldía, los dirigentes del hospital y del Programa Tierradentro determina la vida social y política nasa, pues controla el ingreso de planes y programas a los resguardos, y a su alrededor están los jóvenes estudiados, quienes aun cuando están preparados para asumir responsabilidades dependen de su patrón.

El ingreso a las elites y el trabajo dentro de ellas, muchas veces sin recibir recompensa, permite tener prestigio. Así, en el caso del municipio de Páez algunos trabajos no tienen remuneración económica pero sí otorgan estatus social al ser elegidos por los miembros de los cabildos del municipio. Este estatus se manifiesta por la importancia de hacer parte de un grupo de personas que tienen poder y autoridad y un alto nivel de decisión. Pero cuando hay recompensas, según Keller (I979: I82), ellas desempeñan un doble propósito en el reclutamiento de las minorías pues motivan a los individuos a asumir responsabilidades, lo que estimula al mismo individuo, y conservan el prestigio dentro de ellas, lo que sirve como signo externo de rango.

Como se anotó, aunque los jóvenes se preparan para asumir cargos en sus resguardos la mayoría de los estudiados terminan atrapados por las redes clientelistas que se están formando, mientras su participación local de acuerdo con esos conocimientos es casi nula. En otros casos no existe credibilidad en la capacidad de los estudiantes recién graduados y se prefiere contratar estudiantes de afuera -de Opción Colombia, por ejemplo- ${ }^{24}$. Así que aun cuando en algunas instituciones educativas se reprodu-

24. La Corporación Opción Colombia se creó en I99I como una iniciativa de estudiantes y docentes universitarios, preocupados por la distancia entre la universidad y la realidad del país. Está compuesta por un consejo interuniversitario nacional y un consejo directivo, que cuentan con cuatro unidades: administrativa y financiera, creativa y de comunicación, estudiantes y universidades, y gestión y proyectos. Los estudiantes trabajan un semestre en los municipios colombianos, donde adelantan trabajos de acuerdo con su área de estudio (En http:// www.opcioncolombia.org.co, septiembre de 2002). ce la estructura del cabildo, en la vida cotidiana estos jóvenes encuentran limitaciones para reproducirla, al ser reclutados por las redes clientelistas. Si bien los dineros de las transferencias otorgados a los indígenas después de I99I han permitido la formación de redes de clientela, los han obligado también a 


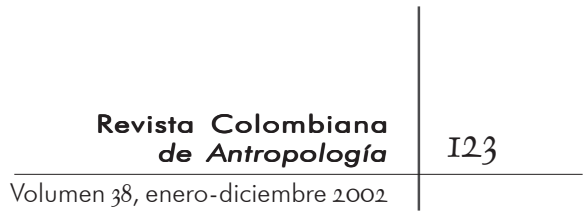

involucrarse dentro de una racionalidad administrativa y burocrática en términos weberianos, lo que de por sí constituye un reto dentro del proceso modernizador de la sociedad y la política.

\section{Política, Administración y desarrollo}

OMO LO SEÑAlamos, DESDE I99I LOS CABILDOS ADMINISTRAN LOS recursos de transferencias desembolsados por el estado central. En algunos $\operatorname{casos}^{25}$, esta administración se entiende como el gasto del dinero, sin tener en cuenta las necesidades de la comunidad y sin llevar libros básicos de contabilidad, lo que crea problemas; en otras oportunidades los cabildos contratan contadores y administradores con el fin de evitarlos. En todo caso, los problemas políticos derivados de la administración de recursos de transferencias han llevado a los indígenas a reflexionar sobre los cambios que se presentan, y las competencias que se requieren para su administración. Surgen entondes demandas por capacitación en administración o contabilidad, como parte fundamental del proceso de modernización que están viviendo.

Los cabildos administran los dineros directamente, pero el municipio es la figura administrativa que los recibe y que avala su inversión, mediante la aprobación de los planes de desarrollo de los resguardos. Si bien la idea del desarrollo ha sido ampliamente cuestionada en el ámbito académico (Escobar, 2000a; 2000b; Ferguson, I994; I996), en este contexto aún representa una posibilidad de cambio para las sociedades indígenas, al tiempo que, una condición a la cual hay que resistir desde el punto de vista cultural. Esta paradoja se ha resuelto parcialmente en la sociedad Páez mediante la formulación de los planes de vida, interpretación local de la idea del desarrollo.

En los municipios de la zona de Tierradentro -Inzá y Páez-y en algunos resguardos se acogió como un requisito la ley 156, de los planes de desarrollo; en Páez, se han elaborado durante dos administraciones, desde I995, de la siguiente manera: la administración municipal recoge la información y la institución contratante analiza y escribe el documento,

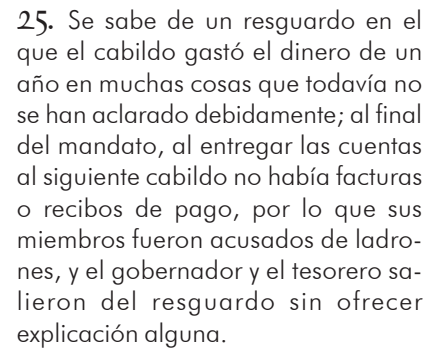
que el cabildo gastó el dinero de un año en muchas cosas que todavía no se han aclarado debidamente; al final del mandato, al entregar las cuentas al siguiente cabildo no había facturas o recibos de pago, por lo que sus miembros fueron acusados de ladrones, y el gobernador y el tesorero salieron del resguardo sin ofrecer explicación alguna. 
que luego envía desde la ciudad a la administración local y al consejo municipal, para su aprobación.

Esos planes se convierten en documentos que reposan en un estante en la casa del cabildo o en la secretaría de planeación del municipio, y no se utilizan como documentos de referencia para las actividades de evaluación y seguimiento a los programas de gobierno o a la inversión de la nación y de los resguardos. Es decir, la mayoría de los planes de desarrollo de los resguardos los hacen instituciones externas a la comunidad, y esta casi no se apropia de ellos, situación apenas comprensible debido a la cultura oral de los paeces.

La relación entre los planes de los resguardos y el plan municipal no es evidente; los planes de inversión de los resguardos no tienen en cuenta los diagnósticos del municipio y viceversa. Además, en estas situaciones la administración municipal funciona como un ente pasivo que avala las inversiones de las transferencias, realizadas en teoría por medio de los planes de desarrollo de los resguardos, sin seguir y evaluar dichas inversiones en las comunidades locales. En el caso anterior, la ley es un requisito no un reconocimiento político; por tanto, su aplicación más que una posibilidad es una obligación en la búsqueda de recursos económicos.

La administración 200I-2003, bajo la dirección de un alcalde elegido por el movimiento indígena, intentó elaborar el plan de desarrollo de otra manera, siguiendo la siguiente metodología: la información se recogió en talleres zonales; luego se analizó, redactó y escribió la parte del documento que le correspondía a cada sección, y se articularon después; finalmente, se aprobó el documento final, con la ayuda de los asesores.

Este cambio en la administración de los recursos puede significar una mayor comprensión sobre las implicaciones de los planes de desarrollo, hecho que puede ratificarse frente a los planes de inversión del municipio, que no se articulan o relacionan con los planes de desarrollo previstos para el resguardo. Aunque la comunidad local se reúne en asamblea para planear la ejecución de los dineros del año siguiente, su uso real lo definen el cabildo y, sobre todo, el gobernador entrante. En estas actividades, los cargos de gobernador y de tesorero tienen mayor importancia, lo más importante es que los individuos adquieren cierto rango y estatus local. Una de las consecuencias de este aspecto es la 


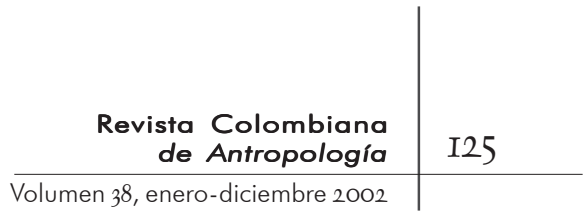

interiorización del cargo; como señalan Berger y Luckmann (I998, 98) "el individuo participa en un mundo social y al interiorizar dichos roles ese mismo mundo cobra realidad para ellos subjetivamente”.

\section{CONCLusión}

OS INDÍGENAS ESTÁN GANANDO, CADA VEZ MÁS, ESPACIOS DE PODER local, regional y nacional, muchos de ellos pagados con la vida. La existencia de los cabildos locales y de las asociaciones de cabildos, adscritas en muchos casos a organizaciones regionales y nacionales, es una manifestación y la base de estos espacios. Sin embargo, y a pesar de los logros políticos, sociales y culturales conseguidos, y de acuerdo con lo observado en el municipio de Páez, la política de los Nasa es mucho más práctica -organizativa-, que ideológica -doctrinaria-, sin demeritar las políticas e ideologías de recuperación cultural que adelantan muchas fundaciones. Los grupos armados, los antropólogos, las instituciones e, incluso, la misma alcaldía, tienen discursos relacionados con la ecología y los derechos humanos, que pocas veces se convierten en actividades concretas.

La promulgación de la carta política de I99I ha permitido encontrar otros espacios de poder, que antes eran de crítica al estado, y se han convertido en la actualidad en espacios que lo representan en las localidades y las regiones, pero sobre todo que albergan elites y redes de clientela local, que al final conforman la burguesía local cuyo centro de acción es la cabecera del municipio. Una expresión de este cambio se da en el hecho de vivir en Páez, y mientras los indígenas de los resguardos salen de ellos para vivir en la cabecera municipal los de la localidad van a Popayán, Cali, Neiva o La Plata (Huila).

En el municipio de Páez se encuentra un sistema clientelista que se incorpora al movimiento indígena y que puede ser parte de clientelas partidistas pero que, sobre todo, tiene que ver con la promulgación de la carta política de I99I, que permitió manejar recursos. ¿Será posible que los indígenas identifiquen estas acciones como tales y que quienes las promueven reciban sanciones? Si bien es cierto que para la obtención del poder pueden desarrollarse relaciones clientelistas, está por investigarse todavía si 
deben seguir persistiendo en el desarrollo de los programas o la manera en que estos sistemas clientelistas se cruzan, pero, sobre todo, cómo se proyecta el estado en esos movimientos-instituciones y convierte a los líderes en sus representantes directos. El éxito de esta política del estado implicaría, entonces, que los líderes que trabajan en esas instituciones comprendieran los objetivos que este se propone al llevarla a cabo. Todo esto permite suponer que para la región Páez no existe un patrón común de relaciones clientelistas en cuanto al acceso al poder y la administración de recursos. Es posible, por el contrario, encontrar un conjunto de situaciones diversas que reflejan la especificidad local en el contexto de sus relaciones sociales.

Así, entonces, el afán de ser políticamente diferentes en sus territorios ha llevado a los indígenas a reproducir estructuras políticas de vieja data. Las preguntas son, ¿cómo sostenerse en el poder cuando se asimilan las acciones políticas que tanto se rechazan? ¿Con qué grupos se establecerán alianzas para fortalecer el movimiento político? ¿Con los negros, minoría étnica en el municipio, o con los mestizos colonos reindigenizados? (véase Rojas y Sevilla, I994). Los indígenas enfrentan el reto de que la forma de hacer política no se convierta en un ciclo repetitivo, y en este momento tienen la oportunidad de demostrarlo.

La constitución política de I99I ha sido la base legal fundamental en la que se han enmarcado las nuevas formas de política y orden y una oportunidad de organización y de reconocimiento de derechos particulares. En el caso analizado, las esferas de la práctica social y política en las que se reconocen como Nasa, incluyendo o excluyendo a otros de su grupo, enmascaran los discursos ideológicos de reivindicación identitaria, expuestos u opacados por otras instituciones y que se convierten en materia para investigaciones futuras.

De otro lado, y comparado con épocas anteriores, el protagonismo religioso y social de la iglesia católica es cada vez menor en relación con la acción de los grupos protestantes, que son cada vez más numerosos y diversos en los resguardos del municipio. La acción de estos grupos sobre la cultura, la sociedad y la política nasa, pero sobre todo las redes de poder en las que se ven envueltos para controlar estos grupos requiere descripciones detalladas y estrategias metodológicas que permitan abordar las relaciones que se presentan. 


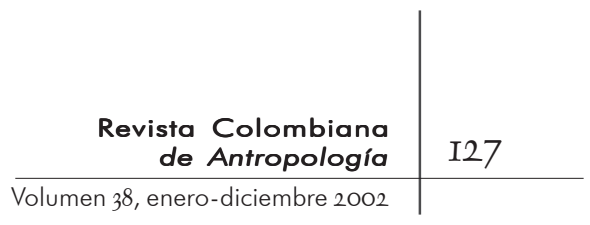

Las estrategias utilizadas por los nasa en sus resguardos para mantener el orden social y político y para revitalizar la cultura de su pueblo serán cada vez más complejas; lo mismo sucede con la estrategia para que el cambio social (imodernidad?) no los lleve a dejar de ser nasa, una premisa no proclamada pero subyacente en las actividades políticas que desarrollan en diferentes escenarios.

\section{BibLIOGRAFÍA}

Bedoya Dorado, Isaac. I99o. "El bastón de chonta. Etnicidad y política en un resguardo Páez del Cauca-Colombia”. Tesis de antropología. Facultad de ciencias humanas y sociales. Universidad del Cauca.

Berger, Peter L. y Luckmann, Thomas. 1998. La construcción social de la realidad. Amorrortu Editores. Buenos Aires.

Berman, Marshall. I99I. Todo lo sólido se desvanece en el aire. La experiencia de la modernidad. Siglo XXI Editores. Bogotá. Quinta edición.

Bonilla, Víctor Daniel. 1977. Historia política de los paeces. Colombia Nuestra Ediciones.

Correa Rubio, François. I992. "Lo "indígena” ante el estado colombiano. Reflejo jurídico de su conceptualización política”. En Antropología jurídica. Normas formales: costumbres legales en Colombia. Ester Sánchez (compiladora). Ediciones Antropos. Bogotá.

Escobar, Arturo. 1999. El final del salvaje. Naturaleza, cultura y política en la antropología contemporánea. Cerec-Ican. Bogotá.

- 2000a. Antropología y desarrollo. En: http://www.unesco.org/ issj/ricsi54/escobarspa.html.

. 200ob. "Beyond the search for a paradigm? Post-development and beyond'. Development. 43: 4.

Ferguson, James. 1994. The Anti-Politics Machine. 'Development', Depoliticization and Bureaucratic Power in Lesotho. University of Minnesota Press. Minneapolis.

— . 1996. "Development”. En Alan Barnard y Jonathan Spencer (editores). Encyclopaedia of Social and Cultural Anthropology. Routledge. Londres y Nueva York.

Gómez, Herinaldy. 1989. Derecho y cultura en el juzgamiento de indígenas. Memorias del V congreso nacional de antropología. Instituto Colombiano de Antropología-Icfes. Villa de Leiva. 
Gómez, Herinaldy y Ruiz, Carlos Ariel. I997. Los paeces: gente territorio. Metáfora que perdura. Funcop-Universidad del Cauca. Popayán.

GonZÁlez, José Antonio. 1994. "El clientelismo social y político en las sociedades mediterráneas". En Antropología. Una exploración de la diversidad humana con temas de la cultura hispana. Conrad Phillip Kottak. McGraw Hill. Madrid. Sexta edición.

Gros, Christian. I997. "Indigenismo y etnicidad: el desafío neoliberal". En Antropología en la Modernidad. María Victoria Uribe y Eduardo Restrepo (editores). Instituto Colombiano de AntropologíaColcultura. Bogotá.

Henman, Anthony. 198ז. Mama coca. Editorial La Oveja Negra-El Áncora Editores. Bogotá.

JACKSON, JEAN. I998. "El impacto de la reciente legislación nacional en la región colombiana del Vaupés". En Modernidad, identidad y desarrollo. María Lucía Sotomayor (editora). Ican-Colciencias. Bogotá.

Jimeno Santoyo, Myriam. I988. "Conflicto interétnico y chamanismo, los paeces". En Memorias del 45 Congreso internacional de americanistas. Ediciones Uniandes. Bogotá.

Keller, Suzanne. 1979. "Elite". En Enciclopedia internacional de las ciencias sociales. Volumen 4.

Laurent, Virginie. I998. "Pueblos indígenas y espacios políticos en Colombia. Tendencias nacionales diferencias regionales". En Modernidad, identidad y desarrollo. María Lucía Sotomayor (editora). Ican-Colciencias. Bogotá.

Leal, Francisco y Dávila, Andrés. 1994. Clientelismo. El sistema político y su expresión regional. TM Editores-Instituto de Estudios Políticos y Relaciones Internacionales. Bogotá.

Opción Colombia. En www.opcioncolombia.org.co

Portela, Hugo. 1988. Yu cee. Universidad del Cauca. Popayán.

- 1995. "Cuerpo y cosmos en los rituales Páez”. En Memorias del ter seminario de etnohistoria del norte del Ecuador y el sur de Colombia. Guido Barona y Francisco Zuluaga (editores). Colección Historia y Sociedad. Facultad de Humanidades. Cali.

Rojas, J. M. y SEvilla, Elías. 1994. "El campesinado en la formación territorial del suroccidente colombiano”. En Renán Silva (editor). Territorios, regiones, sociedades. Cerec-Universidad del Valle. Cali.

Sahlins, Marshall. 1963. "Poor man, rich man, chief: political types in Melanesia and Polynesia". Comparative in Society and History. 5. 


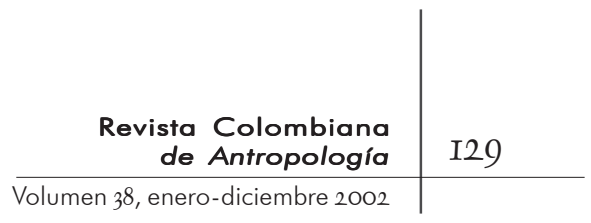

Santana, Roberto. 1995. Los ciudadanos en la etnicidad. Los indios en la política a la política de los indios. Biblioteca Abya Yala. Quito.

Schmidt, W. StefFen. I974. "La Violencia revisited: the clientelist bases of political violence in Colombia". Journal of Latin American Studies. Volumen I.

. 1977. "The transformation of clientelism in rural Colombia". En W. Steffen Schmidt, et al. Friends, Followers and Factions. A reader in Political Clientelism. University of California Press. Berkeley/Los Angeles/Londres.

Sмiтн, M. G. I979. "Modelo conceptual del sistema político". En Antropología política. Compilado por J. R. Llobera. Editorial Anagrama. Barcelona.

Talleres de plan de desarrollo municipio de PÁez, 20OI. Alcaldía municipal, Belalcázar.

ToCANCIPÁ, JAiro. 2000. "Etnografía y análisis de una votación”. En Revista de la Facultad de Ciencias Humanas y Sociales. Volumen 3: 3. Universidad del Cauca. Popayán.

Triana Antorveza, Adolfo. 1992. "Grupos étnicos. Nueva constitución en Colombia”. En Antropología jurídica. Normas formales: costumbres legales en Colombia. Ester Sánchez (compiladora). Ediciones Antropos. Bogotá.

Valencia, Luis Emiro y Poveda, Abdón Alejandro. ig92. "Constitución y pueblos indígenas". En Antropología jurídica. Normas formales: costumbres legales en Colombia. Ester Sánchez (compiladora). Ediciones Antropos. Bogotá.

Zambrano, Carlos. I997. "Diversidad democracia y riesgo. Una perspectiva sociocultural de la sociedad colombiana". En Memorias del VIII Congreso de antropología en Colombia. Ponencia 9. Disco memorias 3 .

\section{Entrevistas}

Joel Fernando Guagás. Estudiante, capitán del cabildo del Seminario Indígena Páez. 26 de febrero de 200I.

Francisca Lucumi. Ama de casa, partera. Diciembre de 2000

Eufemia Perdomo. Ama de casa. Febrero de 200I.

Elías Piñacué Achicué. Estudiante, gobernador del cabildo del Seminario Indígena Páez. 26 de febrero de 200I. 